\title{
Doxorubicin Deteriorates the Histomorphology of the Kidneys of Albino Rats
}

\author{
Pandeya $\mathrm{A}^{1}$, Jha $\mathrm{CB}^{2}$, Karki $\mathrm{S}^{3}$, Rauniar $\mathrm{GP}^{4}$
}

\begin{abstract}
Background and Objectives: Nephrotoxicity is one of the limiting factors for using doxorubicin as an anticancer chemotherapeutic. Reactive oxygen species and cytokines have been implicated in the nephrotoxicity induced by doxorubicin. The main objective of the present study is to identify and compare the histomorphological features in kidneys of albino rats and gross morphological features such as weight of rats and weight of the kidneys due to administration of doxorubicin. Materials and Methods: In the study, albino rats were taken as the animal model. Sixty animals were taken as the sample size. They were divided into two equal groups: experimental $(n=30)$ and control $(n=30)$. Rats of experimental group were treated with anticancer drug doxorubicin at a single intraperitoneal dose of $10 \mathrm{mg} / \mathrm{kg}$ body weight while the Control group of rats received a similar volume of $0.9 \%$ normal saline. The ethical clearance was taken prior to the research from IERB committee BPKIHS Dharan. Results: Our results showed that there was high effect of drug in experimental groups of rats. It was seen that there was significant decrease in the body weight and weight of kidneys. The final body weight and kidney weight between experimental and control group showed the significant difference. Similarly there were no significant differences in the normal architecture between the male and female rats. The normal renal histological features were seen on the kidneys in the control group whereas the rats intervened with the drug had some disrupted histological features which reveal the toxicity of the drugs in the kidneys. Conclusion: The study showed toxicity of the drug in the kidneys of experimental groups of rats irrespective of gender and suggest that doxorubicin causes significant loss of the body weight and weight of kidneys and causes the disruption in the normal histological features.
\end{abstract}

Key words: Doxorubicin, nephrotoxicity, rats

\section{INTRODUCTION}

Doxorubicin, an anthracycline isolated from Streptomyces peucetius, has potent antitumor activity against a wide range of human malignancies ${ }^{1}$. The optimal use of doxorubicin is limited by a number of side effects; the most important are cardiotoxicity, haematotoxicity and a dose limiting nephrotoxicity ${ }^{2}$. Doxorubicin has been used for more than 30 years for the treatment of various malignancies, including tumors in breast tissue, bile duct, endometrial tissue, esophagus and liver as well as osteosarcomas, soft tissue sarcomas, and non-Hodgkin's lymphoma ${ }^{3}$. It acts by inhibiting the enzyme topoisomerase II, which leads to double strand breakage in the DNA double helix and also by intercalating with the DNA ${ }^{4,5}$. The exact mechanism and chance of doxorubicin induced obvious nephrotoxicity is not yet specifically known. However, it has been suggested by many investigators that cellular damage induced by doxorubicin is mediated by the formation of an iron anthracycline free radical ${ }^{6}$. Cardiac and renal damage has also been reported in laboratory animals

\footnotetext{
1. Dr. Anup Pandeya

2. Prof. Chandra Bhushan Jha

3. Prof. Smriti Karki

4. Prof. Gajendra Prashad Rauniar
}

Address for correspondence:

Dr. Anup Pandeya

Department of Anatomy

Devdaha Medical College and Research Institute,

Rupandehi, Nepal

Email: anup.bpkihs@gmail.com following treatment with doxorubicin. Nephropathy has also been reported in cancer patients on doxorubicin therapy, as well as in experimental animals treated with doxorubicin. However, it is not yet clear what duration of doxorubicin therapy induces nephrotoxicity ${ }^{7}$. Doxorubicin induced changes in the kidneys of rats include increased glomerular capillary permeability and tubular atrophy. Nitric oxide is a free radical gas which acts both as a cytoprotective and cytotoxic agent. Nitric oxide is generated by either endothelial nitric oxide synthase or inducible nitric oxide synthase. Possible role of doxorubicin in nitric oxide synthase metabolism occurs via direct or indirect stimulation of nitric oxide production, and this might be a consequence of increased free radical generation. Free radical production and/or nitric oxide release induced by doxorubicin has been found to be responsible for the doxorubicin-induced toxicity ${ }^{8}$. The most frequently investigated effect of Doxorubicin on a molecular level is its tendency to generate a large amount of reactive oxygen species through the formation of semiquinone-type free radicals ${ }^{9}$.

Since kidneys are the important organs for the survival of living beings and anticancer drugs have much more effect on kidneys. Therefore the present study has been designed to identify the histomorphological changes in kidneys of albino rats due to administration of doxorubicin in comparision to control groups.

\section{METHOD AND MATERIALS \\ Animals}

Sixty healthy Wistar Albino rats weighing 150-200gm were obtained from the animal house of BPKIHS, Dharan. They were housed in well ventilated room at controlled ambient 
temperature $\left(25 \pm 5^{\circ} \mathrm{C}\right)$ with a 12 hours alternating light and dark cycle. Animals were kept in groups consisting of less than five rats per cage made up of propylene $($ size $=40 \mathrm{~cm} \times 25 \mathrm{~cm} \times 15 \mathrm{~cm}$ ) with husk bed. The cages were cleaned and husks were changed at regular intervals. The water bottles were also regularly cleaned to inhibit any fungal growth. The ethical clearance was taken prior to the research from Institutional Ethical Review Board (IERB) Committee, BPKIHS Dharan.

\section{Diet Regimen}

All rats were fed standard pellet diet and Bengal gram. They were given tap water and libitum. All the experimental works were carried out as per the ethical guidelines of Nepal Health Research Council (NHRC) for the care and use of animals in health research in Nepal.

\section{Animal Groups and Treatment Regimen}

Rats were randomly divided into three groups:

Group A - Long term (16th week)

The long term group was again divided into two sub-groups

$\mathrm{A} 1=$ Experimental and $\mathrm{A} 2=$ Control

Group B- Mid-term (8th week)

The mid-term group was again divided into two sub-groups

$\mathrm{B} 1=$ Experimental and $\mathrm{B} 2=$ Control

Group C- Short term (2nd week)

The short term group was again divided into two sub-groups $\mathrm{C} 1=$ Experimental and $\mathrm{C} 2=$ Control

\section{Experimental Procedure}

All rats were weighed the time of euthanasia. Animals were anesthetized with ether soaked in cotton and their kidneys were fixed by in vivo perfusion technique as mentioned below. Rats were kept on the dissecting tray with their ventral surface facing upward and all four limbs pinned. The abdomen was opened to expose the abdominal aorta and inferior vena cava. A 18 guage needle was inserted on the abdominal aorta and tied with thread to keep it in constant position. The needle was attached to clean flask tube, connected with two bottles containing bouin's fluid and physiological saline separately.
Then the chest was opened and the right atrium was nicked by a scissor or knife (scalpel) to permit the drainage of blood. Thereafter, the physiological saline was perfused to flush out the blood. The fixative bouin's fluid was then transfused with the help of three ways stopcock. Approximately $200 \mathrm{ml}$ of each fluid was perfused. Perfusion was stopped when clear fixative drops started oozing out from the snout of the animal. After completion of perfusion, the kidneys were isolated with the help of scalpel and forceps and weight was measured and post fixed for 24 hours by the same fixative. After 18 hour fixation in bouin's fluid, the tissue was processed and histological slides were prepared from vertical sections from the polar and the equatorial regions of each kidney. Micrometer was used for quantitative measurement of parameter; diameter of renal corposucles and glomerulus were observed qualitatively in histological slides. Diameter (D) of each renal corpuscles and glomerulus was measured.

\section{Quantitative Measurement}

Ocular and stage micrometers were used for quantitative measurements of different parameters like diameter of renal corpuscles, glomerulus.

\section{Statistical Analysis}

After completion of the experiment, data was entered in the microsoft excel software program. Statistical analysis was performed using the Statistical Package for Social Sciences (SPSS) 16 version. Depending upon the nature of the data collected, statistical tool independent-sample t- test and paired sample t-test were used to determine the significance of histomorphological changes, body and kidney weight and size of cells between experimental and controls. Statistical significance was set at $5 \%$ level of significance.

\section{RESULTS}

In this study, 60 wistar albino rats were taken. They were divided into 2 groups, control and experimental. Control and experimental groups both were again divided into 3 sub-groups each having equal number of male and female rats. The different data of the result showed that there was high effect of the drug in short term, mid-term and long term groups of rats.

\begin{tabular}{|l|l|l|l|l|}
\hline Group & Sub-group & Sample Size & Duration of sacrifice & Treatment Regimen \\
\hline Group A (Long term) & A1 ( Experimental) & 5 males + 5 females & 16th week & $\begin{array}{l}10 \mathrm{mg} / \text { Kg doxorubicin } \\
\text { (intraperitonially) }\end{array}$ \\
\hline \multicolumn{2}{|c|}{ A2 ( Control) } & 5 males + 5 females & $\begin{array}{l}10 \mathrm{mg} / \text { Kg 0.9\% normal } \\
\text { saline (intraperitonially) }\end{array}$ \\
\hline Group B (Mid-term) & B1 ( Experimental) & 5 males + 5 females & 8th week & $\begin{array}{l}10 \mathrm{mg} / \text { Kg doxorubicin } \\
\text { (intraperitonially) }\end{array}$ \\
\hline \multicolumn{2}{|l|}{ B2 ( Control) } & 5 males + 5 females & $\begin{array}{l}10 \mathrm{mg} / \text { Kg 0.9 \% normal } \\
\text { saline (intraperitonially) }\end{array}$ \\
\hline Group C (Short term) & C1 ( Experimental) & 5 males + 5 females & 2nd week & $\begin{array}{l}10 \mathrm{mg} / \text { Kg doxorubicin } \\
\text { (intraperitonially) }\end{array}$ \\
\hline
\end{tabular}


It was observed that mean difference between the initial and the final weight of rats in experimental and control groups was highly significant $(P<0.001)$ in short term, mid-term and long term groups of rats. The mean difference of the weight of right and left kidney in experimental and control groups was not statistically significant $(P>0.05)$ in both short term and long term group of rats whereas the mean difference of the weight of right and left kidney in experimental and control groups of rats was highly significant $(\mathrm{P}<0.001)$ in mid-term group of rats.

In this study we observed that the mean difference between the diameter of renal corpuscles in experimental and control group was not statistically significant $(P>0.05)$ in both short term and long term group of rats whereas the mean difference between the diameter of renal corpuscles of experimental and control group was statistically significant $(P<0.05)$ in mid-term group of rats. And in case of glomerulus the mean difference between the diameter in experimental and control group was statistically significant $(\mathrm{P}<0.05)$ in both short term and long term group of rats whereas the mean difference between the diameter of glomerulus of experimental and control group was not statistically significant $(\mathrm{P}>0.05)$ in mid-term group of rats (Table I).

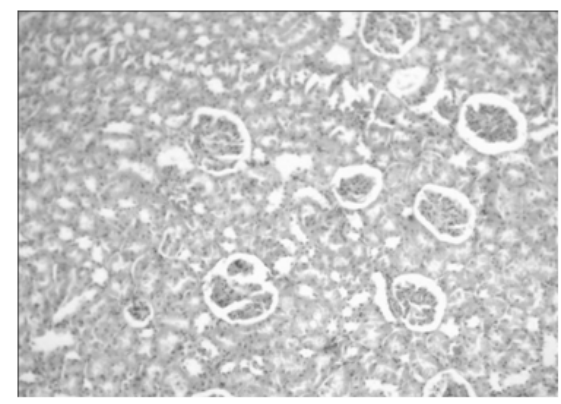

Figure $1 \mathrm{~A}$

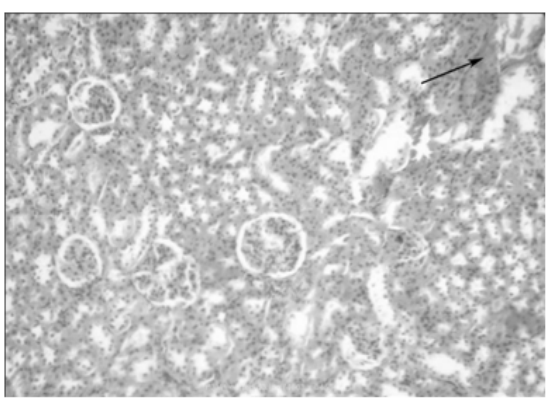

Figure $1 \mathrm{~B}$

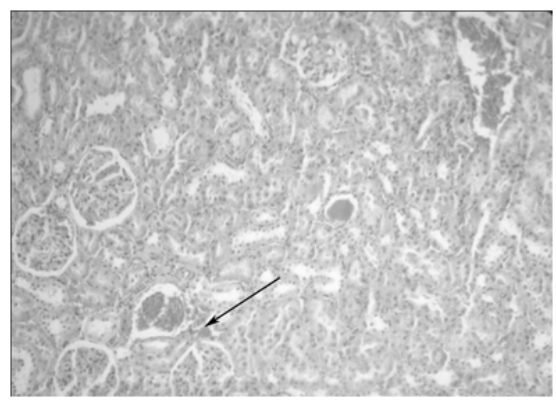

Figure $1 \mathrm{C}$

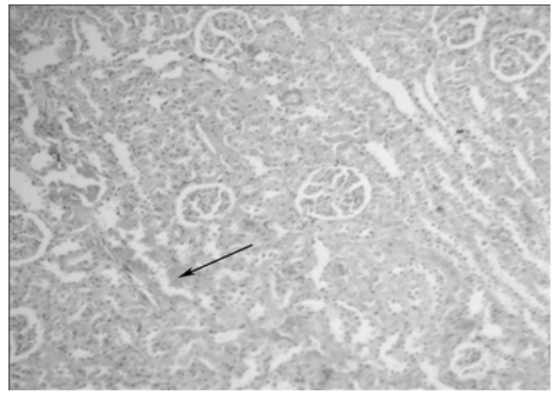

Figure $1 \mathrm{D}$

Figure 1: A, B, C and D show the diameter of renal corpuscles and glomerulus of control (all control groups), short term experimental group, mid-term experimental group and long term experimental group respectively.

\begin{tabular}{|c|c|c|c|c|c|c|}
\hline Parameters & Group C1 & Group C2 & Group B1 & Group B2 & Group A1 & Group A2 \\
\hline $\begin{array}{c}\text { Initial Body } \\
\text { weight }(\mathrm{gm})\end{array}$ & $156.5 \pm 7.09$ & $159.0 \pm 7.37$ & $159.5 \pm 5.98$ & $162.0 \pm 10.05$ & $170.0 \pm 12.47$ & $160.5 \pm 7.24$ \\
\hline $\begin{array}{c}\text { Final Body } \\
\text { Weight (gm) }\end{array}$ & $148.0 \pm 7.52$ & $165 \pm 9.12$ & $147.0 \pm 5.37$ & $181.5 \pm 15.46$ & $158.0 \pm 8.88$ & $178.5 \pm 16.5$ \\
\hline $\begin{array}{c}\text { Kidney Weight } \\
(\mathrm{gm})\end{array}$ & & & & & & \\
\hline Right & $0.69 \pm 0.08$ & $0.70 \pm 0.09$ & $0.67 \pm 0.06$ & $0.82 \pm 0.09$ & $0.79 \pm 0.90$ & $0.81 \pm 0.05$ \\
\hline Left & $0.65 \pm 0.08$ & $0.66 \pm 0.09$ & $0.63 \pm 0.06$ & $0.80 \pm 0.10$ & $0.76 \pm 0.07$ & $0.77 \pm 0.05$ \\
\hline $\begin{array}{c}\text { Diameter of } \\
\text { Renal } \\
\text { Corpuscles }(\mu \mathrm{m})\end{array}$ & $120.0 \pm 15.81$ & $112.0 \pm 11.11$ & $113.5 \pm 10.029$ & $125.5 \pm 10.92$ & $131.5 \pm 12.48$ & $121.0 \pm 13.9$ \\
\hline $\begin{array}{c}\text { Diameter of } \\
\text { Glomerulus } \\
(\mu \mathrm{m})\end{array}$ & $100.5 \pm 14.23$ & $87.0 \pm 11.11$ & $97.5 \pm 7.91$ & $89.5 \pm 10.92$ & $108.5 \pm 12.03$ & $93.5 \pm 15.28$ \\
\hline
\end{tabular}

Table I: Changes in morphometric parameters in albino rats 


\section{DISCUSSION}

Anticancer therapy usually demolishes the physiological homeostasis and affects multiple organs during treatment process. Effective anticancer therapy with anthracycline is limited because of its toxicity to various organs including kidneys $^{10}$. The toxicity has been attributed to radical formation and oxidant injury. Nephrotoxic action of doxorubicin is also considered to be via drug induced free radical generation. The formation of free radical as well as an increase in response to doxorubicin treatment has already been documented. The disturbance in oxidant- antioxidant systems results in tissue injury that is demonstrated with protein oxidation in tissues and protein oxidation in renal tissue is recognized as one of the possible biochemical mechanisms of doxorubicin induced nephrotoxicity ${ }^{11}$.

The study was designed with the rationale to find out the effect of the doxorubicin in the kidneys. In this study, albino rats were taken as the animal model. 60 rats were taken as the sample size. The rats of long term group of both control and experimental were sacrificed together after 16th week of intervention. Similarly the rats of mid-term and the short term group of both control and experimental were sacrificed together after $8^{\text {th }}$ week and $2^{\text {nd }}$ week of intervention respectively. The experimental groups were given single dose of $10 \mathrm{mg} / \mathrm{kg}$ body weight of doxorubicin intraperitoneally and control groups were given normal saline of equal volume of the drug. The kidney section of control group showed normal histological feature of the kidney similar to those observed by other researcher. The reduction in animal body weight in experimental group may be attributed to the cytotoxic effect of doxorubicin since it cause myelosupression, anemia, loss of appetite and poor feeding, or it may inhibit protein synthesis.

In the present study the experimental group of rats demonstrated the general weakness, loss of appetite and reduction in body weight. The weight loss might be due to the loss of appetite causing mobilization and utilization of fat and change in metabolic rates. However, the final weight of rats of control groups demonstrated increase in body weight. This result is similar from the study conducted by Boonsanit $D$ et al. which shows that doxorubicin affects the growth of rats with significant reduction in daily food intake and body weight ${ }^{12}$.

The results in the present study showed the increase in diameter of renal corpuscles and glomerulus in the doxorubicin injected rats as compared to control group of rats. Similar result was observed in the study done by Rashid S et al. which showed that normal renal architecture was observed in control group whereas renal lesions, inflammation, glomerular congestion and interstitial hemorrhage were observed in doxorubicin treated groups ${ }^{13}$.

\section{CONCLUSION}

In summary, present study demonstrated decreased in the body weight and weight of kidneys in all experimental groups of rats as well as deteriorative effect of doxorubicin was observed on both glomerulus and renal corpuscles of albino rats. The histomorphological adverse changes occur in kidneys of all the experimental groups of rats without gender variation due to administration of doxorubicin.

\section{REFERENCES}

1. Acker SA, Voest EE, Beems DB, Madhuizen HT., Jong JD, Bast A et al. Cardioprotective Properties of O-( $\beta$-Hydroxyethyl)-rutosides in Doxorubicin-pretreated BALB/c Mice. Cancer Research 1993; 53:4603-7.

2. Mansour M A, El-Kashef H A, Al-Shabanah O A. Effect of captopril on doxorubicin-induced nephrotoxicity in normal rats. Pharmacol Res 1999; 39(3): 233-37.

3. Menna P, Salvatorelli E, Cairo G, Gianni L. Anthracyclines: molecular advances and pharmacologic developments in antitumor activity and cardiotoxicity. Pharmacol Rev 2004;56:185-229.

4. Chabner BA, Ryan DP, Paz-Ares L, Garcia-Carbonevo R, Calabresi P. Antineoplastic agents. Goodman and Gilman's the pharmacological basis of therapeutics, 10th edition, New York: McGraw-Hill; 2001. p. 1389-1459.

5. Quiles JL, Huertas JR, Battino M, Mataix J, Ramirez- Tortosa MC. Antioxidant nutrients and adriamycin toxicity. Toxicology 2002; 180:79-95.

6. Shinde N, Jagtap A, Undale V, Kakade S, Kotwal S, Patil R. Protective effect of Lepidium sativum against doxorubicininduced nephrotoxicity in rats. RJPBCS 2010; 01(03):42-49.

7. Giri SN, Al-Bayati MA, Du X, Schelegle E, Mohr FC, Margolin SB. Amelioration of doxorubicin-induced cardiac and renal toxicity by pirfenidone in rats. Cancer Chemother Pharmacol 2004;53:141-50.

8. Ayla S, Seckin I, Tanriverdi G, Cengiz M, Eser M, Soner BC et al. Doxorubicin Induced Nephrotoxicity: Protective Effect of Nicotinamide. Int J Cell Biol 2011; 2011:1-9.

9. Injac R, Radic N, Govedarica B, Perse M, Cerar A, Djordjevic A et al. Acute doxorubicin pulmotoxicity in rats with malignant neoplasm is effectively treated with fullerenol $\mathrm{C} 60(\mathrm{OH}) 24$ through inhibition of oxidative stress. Pharmacol Rep 2009; 61: 335-42.

10. S. Hertzan-Levy, R. Fish, E. Skutelsky et al., "Glomerular basement membrane anionic sites in Adriamycin nephropathy: effect of saline loading and nitric oxide modulation," Nephron 2000;84(4): 354-361.

11. A. Karaman, E. Fadillioglu, E. Turkmen, E. Tas, and Z. Yilmaz, "Protective effects of leflunomide against ischemiareperfusion injury of the rat liver," Pediatric Surgery International 2006;22(5):428-434.

12. Boonsanit D, Kanchanapangka S, Buranakarl C. L-carnitine ameliorates doxorubicin-induced nephrotic syndrome in rats. Nephrology 2006; 11:313-320.

13. Rashid S, Ali N, Nafees S, T AS. Alleviation of doxorubicin-induced nephrotoxicity and hepatotoxicity by chrysin in Wistar rats. Toxicol Mech Methods 2013; 23(5): 337-45. 